\title{
A ORGANIZAÇÃO ESCOLAR E O TRABALHO DOCENTE DE PROFESSORES INICIANTES DE EDUCAÇÃO FÍSICA DE CRICIÚMA-SC 1
}

\author{
Victor Julierme Santos da Conceição \\ Universidade do Extremo Sul Catarinense, Santa Catarina, Criciúma, Brasil \\ Jessica Serafim Frasson \\ Universidade Federal do Rio Grande do Sul, Rio Grande do Sul, Porto Alegre, Brasil \\ Camila da Rosa Medeiros \\ Universidade Federal do Rio Grande do Sul, Rio Grande do Sul, Porto Alegre, Brasil \\ Elisandro Schutz Wittizorecki \\ Universidade Federal do Rio Grande do Sul, Rio Grande do Sul, Porto Alegre, Brasil \\ Hugo Norberto Krug \\ Universidade Federal de Santa Maria, Rio Grande do Sul, Santa Maria, Brasil
}

\section{Resumo}

Este estudo tem como objetivo compreender como a organização escolar, articulada ao trabalho docente, influencia a prática educativa e as condições de trabalho dos professores iniciantes de Educação Física. Investigamos a prática educativa e as condições de trabalho de seis professores que atuam em escolas municipais. $\mathrm{O}$ instrumento escolhido foi uma entrevista semiestruturada. Compreendemos que a organização escolar possui papel fundamental no contexto escolar quando articulada ao trabalho docente, proporcionando a socialização entre os pares, e que as condições de trabalho oferecidas aos professores podem influenciar tanto o desinvestimento como o processo de descoberta da docência.

Palavras-chave: Organização Escolar. Trabalho Docente. Professor de Educação Física Iniciante.

\section{Introdução}

Ao falarmos sobre professores iniciantes sentimos a necessidade de caracterizá-los. Marcelo Garcia (2010) e Reali, Trancredi e Mizukami (2008) apresentam o docente em início de carreira como aquele que está entre os primeiros cinco anos de atuação docente. Para Marcelo Garcia (2010), é neste período que se dá o confronto dos conhecimentos estabelecidos na formação inicial com as vivências do dia a dia docente. Neste sentido, a organização escolar merece um estudo mais detalhado, na medida em que se deseja

\footnotetext{
${ }^{1}$ Pesquisa financiada pela CAPES.
} 
decodificar os elementos que nela se revelam e, ao mesmo tempo, identificar os direitos e deveres dos docentes nessa organização.

E compreendendo a complexidade de conceituação, e analisando a singularidade do contexto escolar, nos embasamos em Tardif e Lessard (2005, p. 55) quando afirmam que a escola "é um espaço sócio organizacional no qual atuam diversos indivíduos ligados entre si por vários tipos de relações mais ou menos formalizadas [...]”. A organização escolar abrange todo um contexto, onde os seus sujeitos atuam simultaneamente, e cada sujeito exerce sua função, em diferentes lugares e posições, ou seja, os professores na sala de aula, junto aos alunos, construindo conhecimento; os pais, em casa e na escola, procurando incentivar seus filhos; a direção e gestores, à frente do contexto, com as funções burocráticas; e os demais funcionários, no andamento das tarefas diárias da escola.

Neste sentido, Cancherini (2009) apresenta o acolhimento institucional, entendido como aquele que inclui os colegas, diretores e pais nas relações docentes, assim como o currículo e a administração, ou seja, todo o contexto se mobiliza para tal processo. Frasson et al. (2014) corrobora com a ideia ao afirmar que a organização escolar assume protagonismo no contexto educacional, construindo uma "ponte" para a socialização dos professores iniciantes e também a ambientação destes na cultura escolar.

Assim, ao tratarmos a organização escolar como uma ponte para a prática educativa dos docentes, entendemos que esta pode influenciar no trabalho dos professores iniciantes. Então, sentimos a necessidade de compreender o trabalho docente com o intuito de elencar subsídios para analisar o processo de articulação entre organização escolar e trabalho docente, nos contextos de ensino aprendizagem.

No transcorrer da experiência social, o homem vai acumulando e absorvendo formas de realizar determinadas atividades, tais como: entender a realidade, comunicar e expressar sentimentos, sentir que esses se transformam com o desenvolvimento das relações sociais, constituídas pelos homens para a produção de sua sobrevivência. Segundo Santos (2007), o homem enfrenta o mundo e luta contra ele. A autora completa que essa luta não se situa no campo da liberdade, e sim no da necessidade. Homem e natureza lutam entre si. Trata-se de um agir intencional, que tem por finalidade a alteração da realidade.

Basso (1998, p. 4) afirma que no caso dos professores, o significado do trabalho é formado pela finalidade de "[...] [a] ação de ensinar, isto é, pelo seu objetivo e pelo conteúdo concreto efetivado através das operações realizadas conscientemente pelo professor [...]".

Com o intuito de identificar, de modo efetivo, o significado do trabalho docente, é importante destacar a ação intercessora realizada por outro ou por outros indivíduos no procedimento de apropriação dos resultados da prática social (BASSO, 1998). Assim, analisando que a organização escolar necessita estar articulada ao trabalho docente para que haja uma melhor aproximação dos professores iniciantes com o contexto, nos apropriamos de autores que debatem o trabalho docente a partir de uma perspectiva crítica (APPLE, 2001; GIROUX, 1997).

Apple (2001), ao discutir sobre o trabalho docente em seus estudos, enfatiza elementos que tratam da intensificação do trabalho, ou seja, de professores que, pelas próprias condições objetivas, se submeteram a uma ampliada carga de trabalho. Nesse sentido, Pérez Gómez (1998) afirma que o trabalho docente é marcado pelas transformações que ocorrem na contemporaneidade, exigindo que os mesmos construam o que Woods (1998) aponta como estratégias de sobrevivência, para que consigam lidar com o contexto escolar.

Giroux (1997, p. 176) caracteriza os professores como trabalhadores reflexivos, “[...] o 
trabalho dos docentes como uma forma de tarefa intelectual, em oposição a uma definição do mesmo em termos puramente instrumentais ou técnicos". Assim, partindo de uma perspectiva crítica, o trabalho docente vai além do "dar aulas", pois envolve uma série de fatores que mobilizam o ser professor, e que esse precisa de apoio emocional, psicológico e material da organização escolar.

Consequentemente, os professores enfrentam imprevistos diariamente. Segundo Tardif e Lessard (2005), os docentes se confrontam com dilemas e pressões do ambiente escolar: trabalho solitário e trabalho coletivo, autonomia na classe e controle na escola, tarefa prescrita e tarefa real, currículo formal e currículo real, educação e instrução dos alunos. Os autores ainda observam que o trabalho docente "[é] também a atividade de pessoas que não podem trabalhar sem dar sentindo ao que fazem, é uma interação com outras pessoas: os alunos, os colegas, os pais, os dirigentes da escola, etc.” (TARDIF; LESSARD, 2005, p. 38).

Partindo deste entendimento é que apresentamos o objetivo da pesquisa: "compreender como a organização escolar articulada ao trabalho docente influencia na prática educativa e nas condições de trabalho dos professores de Educação Física iniciantes na escola pública".

Assim, compreendemos que, como professores iniciantes, passamos por inúmeros enfrentamentos no contexto de ensino-aprendizagem, enfrentamentos gratificantes e outras vezes conflitantes. Momentos em que nos deparamos com a realidade existente, os quais podem influenciar positivamente ou negativamente a prática educativa. Ainda em meio às dificuldades, os professores passam a se descobrir e querer, de fato, efetivar e dar sentido ao trabalho ou desinvestir e abandonar a docência.

Algumas dúvidas surgem ao pensarmos sobre os papéis dos sujeitos no contexto de ensino-aprendizagem: quem faz a mediação entre os iniciantes e o contexto? Em quem os professores devem se apoiar? A quem recorrer? Neste sentido é que esta pesquisa surge, justamente pela necessidade de compreensão dos papéis exercidos no contexto de ensinoaprendizagem. Professores iniciantes sentem a falta do vínculo com a cultura escolar e precisam de apoio e auxílio durante sua entrada na carreira.

\section{Decisões Metodológicas}

Identificamos esta pesquisa como descritiva de caráter qualitativo "que tem como pressuposto científico manipular informações recolhidas, descrevendo e analisando-as para num segundo momento interpretar e discutir à luz da teoria" (NEGRINE, 2010, p. 62). Entendemos que na pesquisa qualitativa, à medida que as informações são coletadas, ocorre a interpretação, ou seja, assim que a pesquisa vai se estruturando, a interpretação dos dados já é realizada, o que pode originar a necessidade de procura de novos dados com os instrumentos (TRIVIÑOS, 1987).

Partindo de um diagnóstico inicial na cidade de Criciúma - Santa Catarina (SC), identificamos 19 professores de Educação Física contratados em caráter temporário (ACT). Os professores nessa condição de trabalho possuem um contrato com data de início e fim nas escolas, que é estabelecido pela instituição contratante, a prefeitura municipal. Os professores ACT não necessariamente precisam estar formados, ou seja, podem estar cursando o ensino superior e prestar o processo seletivo. Deste modo, identificando essas singularidades nesse contrato temporário dos professores, é que nos propomos a realizar a pesquisa com os professores que possuíam esse tipo de vínculo empregatício.

Primeiro, entramos em contato com os 19 professores, identificando quantos desses se 
aproximavam dos nossos critérios de seleção. Assim, os colaboradores foram selecionados pelas suas cargas horárias (20, 30 ou 40 horas); se trabalhavam em uma ou mais escola; se possuíam vínculo empregatício apenas em Criciúma; e se se encontravam nos primeiros cinco anos de atuação docente. Professores foram selecionados, ainda, a partir da participação espontânea, levando em consideração a iniciativa em buscar participação direta na investigação. Esse tipo de participação influencia positivamente no volume e credibilidade de informações disponibilizadas pelos colaboradores (MOLINA NETO, 2010). Deste modo, a partir dessas singularidades, selecionamos seis dos 19 professores, três mulheres e três homens, todos considerados professores iniciantes e que trabalham em escolas de distintas regiões do município.

Para manutenção dos aspectos éticos da investigação, os colaboradores foram identificados com nomes fictícios, para que dessa forma fossem preservadas suas identidades. Os professores colaboradores assinaram o Termo de Consentimento Livre e Esclarecido, afirmando a concordância na participação da pesquisa. No quadro a seguir, apresentamos as características dos colaboradores, quanto ao tempo de atuação na escola e a idade.

Quadro 1 - Caracterização dos professores participantes da pesquisa.

\begin{tabular}{|l|c|c|c|c|}
\hline Colaboradores & Idade & Carga horária & Quantas escolas & Tempo de atuação \\
\hline Marta & 24 anos & $40 \mathrm{~h}$ & 2 & 3 anos \\
\hline Marcos & 22 anos & $20 \mathrm{~h}$ & 1 & 2 anos \\
\hline Antônio & 22 anos & $20 \mathrm{~h}$ & 1 & 1 ano \\
\hline José & 22 anos & $20 \mathrm{~h}$ & 1 & 6 meses \\
\hline Joana & 28 anos & $40 \mathrm{~h}$ & 2 & 2 anos \\
\hline Maria & 23 anos & $30 \mathrm{~h}$ & 2 & 2 anos \\
\hline
\end{tabular}

Utilizamos como instrumento de coleta de dados a entrevista semiestruturada, construída a partir dos objetivos da pesquisa e validada quanto a sua objetividade e fidedignidade por três professores pesquisadores, que analisaram o instrumento e produziram o parecer sobre o mesmo. Para Negrine (2010),

[é] "semiestruturada" quando o instrumento de coleta está pensando para obter informações de questões concretas, previamente definidas pelo pesquisador e, ao mesmo tempo permite que se realizem explorações não previstas, oferecendo liberdade ao entrevistado para dissertar sobre o tema ou abordar aspectos que sejam sobre o que pensa (p. 76).

Como procedimentos de coleta de dados, realizamos o agendamento das entrevistas com os professores, realizadas em locais e momentos escolhidos pelo professor, atribuindo ao mesmo o protagonismo no processo metodológico. As entrevistas foram gravadas, transcritas e passaram por um processo de validação interpretativa quando apresentadas aos colaboradores, para análise da fidedignidade das informações. As análises dessas entrevistas foram apresentadas a seguir, sendo organizadas em categorias que emergiram das unidades de significados, a partir das falas dos colaboradores.

Desse modo, as entrevistas versaram sobre temas que tem como propósito responder ao objetivo desta pesquisa: a relação da organização escolar com a prática educativa dos professores iniciantes; as primeiras experiências no contexto escolar; o acolhimento e 
socialização com os sujeitos da cultura escolar; as condições de trabalhos ofertadas aos professores e o investimento ou desinvestimento na carreira docente.

Buscamos preservar todos os aspectos éticos da pesquisa, mantendo o processo de validação dos instrumentos e dos dados coletados com os participantes, assim como preservar a identidade dos mesmos e das escolas onde atuam.

\section{Organização escolar como ponte para a construção da prática educativa do professor iniciante}

Nesta categoria, buscamos compreender a relação da organização escolar na prática educativa dos professores no início da carreira docente. Assim, tratamos sobre a organização escolar a partir do seguinte questionamento: Qual a importância atribuída pelo professorado à organização escolar? Algumas unidades de significado aparecem com potência nas falas dos professores: acolhimento, apoio, auxílio, segurança, confiança, autonomia. Essas unidades nos possibilitam refletir sobre a importância da organização escolar em contexto e, principalmente, como ela intermedeia essa ligação com a construção da prática educativa dos professores em início de carreira.

As vivências que os professores possuem ao ingressar na docência, ora como estagiários ora como professores titulares, se tornam experiências, mas que por si só não agregam valores à prática educativa dos professores, ou seja, as reflexões sobre elas são cruciais para o processo crítico-reflexivo.

Substituição de professor, sem experiência nenhuma, precisaram de mim e fui ajudar um colega. Depois, vieram os estágios obrigatórios (Professor Antônio).

Meu primeiro contato na escola foi como professor auxiliar, fiquei na função de ajudar a professora, e também na gestão da escola (Professor Marcos).

A primeira vivência foi com estágio não obrigatório, que eu estava na $5^{\mathrm{a}}$ fase. É, foi na escola de Educação Infantil (Professora Maria).

Zeichner (1980) entende esse processo de aprendizado a partir das experiências como "mito" ao se referir à crença de que as experiências práticas contribuem para formar melhores professores. Nesse direcionamento, Almeida e Fensterseifer (2011, p. 251) destacam a "valorização da experiência e do saber da experiência como possibilidade de conhecer, fazer e conhecer com esse fazer". Assim, a experiência não é o que nos acontece, ou o que passamos, mas o que fizemos com o que nos aconteceu, com o que se passou.

Fundamentados neste pressuposto, compreendemos que os professores se constroem na organização escolar, em um ambiente positivo, de acolhimento e recepção, no contexto de ensino-aprendizagem. Identificamos esses elementos nas falas dos colaboradores, pois ao encararem a realidade pela primeira vez, ou para dar continuidade à prática, os professores precisam do auxílio da organização para que reconheçam determinada cultura, e ainda para que se constituam na escola. Podemos perceber nas falas do professor Antônio que a direção estava presente nesse momento:

Quando comecei a lecionar, quando possuía a minha turma, as equipes diretiva e pedagógica me encaminharam a minha sala e me apresentaram à escola (Professor Antônio). 
Percebemos que acolher e acompanhar os docentes faz parte do processo socializador para com todos os sujeitos do contexto escolar, e isso só tem a acrescentar no processo de iniciação docente e na continuidade de sua prática educativa. Na fala dos professores José e Maria isso faz muito sentido e, além do apoio, ainda é possível vivenciar uma troca de aprendizados entre as partes.

Meu acompanhamento inicial foi com as professoras da classe na qual eu trabalhava que me deram aberturas de mostrar meus conhecimentos, incentivaram e me ensinaram todo o tempo (Professor José).

Eu sempre estive acompanhada de um professor, que me ajudava bastante, e qualquer situação em que tivesse de resolver, eu tinha um suporte da direção, assim foi o que me auxiliou bastante ali no início na minha primeira experiência (Professora Maria).

Ao contrário disso, há casos em que os professores não são apresentados aos demais, não há uma preocupação em receber esses docentes, e muito menos em oferecer subsídios para que possam exercer sua prática educativa. Podemos observar isso nas falas das professoras Marta e Joana:

Eu fui jogada dentro de uma escola pela falta de professores e sem supervisores. Tive que estudar e me preparar sozinha. Pra mim até enfrentar os alunos, por serem alunos de três a seis anos. Foi na cara e na coragem (Professora Marta).

Eu não tive nenhum acompanhamento no início da carreira. Eu senti muita dificuldade porque a equipe diretiva era bem relapsa, não dava muito apoio pra gente na questão de acompanhamento (Professora Joana).

Marcelo Garcia (2010, p. 32) aponta isto como um desprestígio profissional, um descaso não só com os professores, mas também com a própria profissão.

Não é comum que um médico recém-formado deva realizar uma operação de transplante de coração. Nem muito menos que um arquiteto com pouca experiência assine a construção de um edifício de moradias. Sem falarmos que se deixe um piloto com poucas horas de voo comandar um Airbus 340.

Com as professoras Marta e Joana, foi perceptível que ao ingressar na docência foram "arremessadas" em sala de aula. Para Marcelo Garcia (2010), além de manter o equilíbrio pessoal, eles precisam adquirir conhecimento pessoal e profissional para poder trabalhar, o que, no entanto, pode dificultar seu processo de reflexão. O processo de acolhimento docente influencia não só na reflexão, segurança e confiança dos professores, mas também envolve a autonomia frente ao contexto educacional e ao trabalho docente. Ou seja, oportuniza a participação efetiva nas questões de ordem geral da escola, como a gestão, a carga horária, o regimento escolar, a grade curricular, a matrícula, o tempo, o espaço, as relações intersubjetivas, o projeto político pedagógico, entre outros aspectos (CONTRERAS, 2012).

A este respeito, citamos a fala do Professor Marcos:

Sempre tive uma equipe disposta a me ensinar, acredito que entendem como 
é o início da docência, e como é importante uma boa recepção dos mesmos, sendo que nos permite conseguir lecionar e participar da escola com mais autonomia (Professor Marcos).

Percebemos na fala acima a importância da autonomia dada aos docentes. Ao delimitar a área de intervenção da prática pedagógica do professor, corre-se o risco de, talvez, descomprometê-lo da possibilidade de pensar a organização escolar conforme suas necessidades, possibilidades e limites de ação-reflexão, fazendo com que a função docente seja reduzida à aplicação de programas e pacotes didáticos (CONTRERAS, 2012). Também a própria compreensão do trabalho docente pelos professores fica prejudicada . Ao não se sentir capaz ou responsável pelo pensar-fazer a escola, deixam de se envolver com as outras relações pedagógicas que acontecem no seu contexto sociocultural. Para Contreras (2012), existem casos em que os professores não possuem uma relativa autonomia no contexto. Apesar do processo de racionalização e controle do trabalho docente, o sentimento de insegurança se evidencia.

Me sentia pela metade, parece que o nosso trabalho é vigiado pelos outros e a qualquer momento pode ser cortado. Ficava com dúvidas, pois tinha total autonomia para debater questões referentes às minhas turmas, meus materiais, mas quando não era isso, era reunião com pais, entrega de boletins, e até sobre reprovação de aluno, nem ficava sabendo (Professor Antônio).

Neste sentido, Tardif e Lessard (2005) apontam que a escola delimita a estrutura do espaço autônomo. Ao tratar sobre o modelo de organização burocrática, os autores afirmam que o trabalho se distancia das mãos dos professores, pois é estipulado por organizações que estão além da escola. Isso fica evidente na fala do professor Antônio, acima, pois ele se sentia "[...] pela metade, cortado, recebendo um determinado limite".

O modelo de organização escolar influencia diretamente as condições de trabalho oferecidas aos professores iniciantes. Os professores trabalham alicerçados na organização escolar, pois é perceptível que necessitam da "ponte" entre si e o contexto para a construção da prática educativa. Na próxima categoria de análise apresentamos elementos que levam ao desinvestimento ou despertam os professores para a prática reflexiva na docência. Buscamos debater que a desistência ou permanência ali, recebe influência das condições de trabalho oferecidas pela organização escolar no início de carreira.

\section{Condições de trabalho: desinvestimento e desistência $\mathrm{x}$ investimento e permanência}

Nesta categoria, objetivamos compreender como determinadas condições de trabalho influenciam na prática educativa dos professores de Educação Física. Ao tratarmos com os colaboradores sobre a temática central da categoria - o desinvestimento e investimento alguns subtemas foram comuns e outros, singulares, os quais deram origem às nossas unidades de significado: auxílio aos estudantes, gratificação, choque com o real, distanciamento entre teoria e prática, falta de material pedagógico, apoio e desvalorização da disciplina.

Ao analisarmos os elementos que caracterizam o desinvestimento do professorado, nos apropriamos do entendimento de Huberman (1995), ao destacar que o desinvestimento é o 
momento em que os professores passam a dar mais atenção aos seus interesses pessoais que a sua carreira docente, fato que se reflete nas suas práticas educativas e no contexto educacional. Compreendemos que vários são os elementos que podem ocasionar um desinvestimento no professor iniciante e, assim, começamos com o choque inicial que o docente sente, apontado pelo professor José, ao se deparar com as realidades educacionais existentes:

A primeira impressão da realidade de cada escola dá um choque no primeiro momento, pelas condições de trabalho encontradas, falta de apoio, materiais e até mesmo o salário (Professor José).

Hubermam (1995) e Marcelo Garcia (2010) tratam sobre o distanciamento entre o ideal e o real, ou seja, os professores apontam em suas falas que encontram dificuldades em realizar suas práticas educativas pela falta de subsídios proporcionados na graduação.

Da graduação para a prática é um pouquinho diferente [...]. Durante a graduação parece ser tudo bem claro, bem fácil, bem lindo, bem bonito, mas na realidade aparecem muitas dificuldades que a graduação não nos prepara, infelizmente (Professora Joana).

Quando tento ligar teoria na prática vejo que na teoria é tudo muito bonito. A gente até tenta, mas falta material, é difícil, fazer a criança aprender um passe tendo somente uma bola pra 30 alunos é praticamente impossível. A gente tenta agregar a teoria à prática, mas nem sempre a gente consegue (Professora Maria).

Pérez Gómez (1997) apresenta três polos interligados que procuram aliar a técnica como embasamento da função de professor: o primeiro, a dicotomia entre teoria acadêmica e prática docente; o segundo, ir além do pensamento de que a formação inicial deve ter como produto final um profissional pronto para atuar e encarar as realidades encontradas no cotidiano escolar; o terceiro, a superação da ideia de que há uma relação entre os processos de ensino e os processos de aprendizagem.

Ao mesmo tempo que alguns relatam que existe um distanciamento entre a formação inicial e as realidades, outros apontam que os estágios e os conhecimentos adquiridos na graduação foram significativos, ou seja, se aproximaram à realidade escolar. Assim, apontamos a fala do professor Antônio quanto à seu entendimento sobre a formação inicial, e ainda sobre a teoria e a prática.

A formação inicial é como o nome diz, apenas o início, os estágios te auxiliam a ingressar, a conhecer um pouco da realidade, o restante nós devemos fazer. Sobre a teoria, tento sempre trazê-la para minhas aulas, sempre busco relacionar com a prática, por os pés no chão e não ficar no campo das ideias. Acredito que isso é essencial, buscar, refletir, mudar, isso é a práxis (Professor Antônio).

Assim, podemos perceber a importância de o professor em formação, o professor iniciante e, também, o professor experiente conseguirem realizar uma análise de conjuntura, ou seja, fazer uma ampla leitura da realidade, pois assim fica mais fácil perceber as lacunas que a teoria deixa em relação à prática. Essa visão reflexiva e crítica contribui para melhor 
compreensão sobre a teoria e sobre como ela se configura na prática educativa. Para Freire (1987, p. 21), o que para nós conceitua e baliza o ato de reflexão sobre a prática educativa "a práxis, é a reflexão e ação dos homens sobre o mundo para transformá-lo [...]".

Outros motivos como questão salarial, desvalorização da própria disciplina, falta de interesse dos alunos, falta de materiais pedagógicos, falta de apoio da organização escolar, dão ênfase ao elemento que apontamos a partir das falas dos colaboradores, como desinvestimento pedagógico. Ou seja, a postura adotada por aqueles professores que, continuam a atuar nas escolas, no entanto, não investem em práticas pedagógicas de qualidade, não refletindo criticamente e não avançando em sua prática educativa.

A fala da professora Joana propõe analisar até que ponto esses fatores dificultam a prática, a ponto de quererem abandonar a carreira docente, ou ainda, continuarem sua prática educativa sem um comprometimento crítico e reflexivo, apenas "fazer por fazer". E, nesse sentido, apresentamos as falas, onde o desinvestimento pode levar ao abandono da docência.

Me desmotiva muito é quanto ao mal comportamento da maioria dos alunos o que os levam a terem tanta falta de respeito com os professores e colegas. Eu sempre me pergunto isso. A maioria não valoriza o que está disponível e não tem o entendimento de quanto a educação é importante né, vão perceber isso, talvez, daqui há muitos anos, quando eles precisarem (Professora Joana).

As dificuldades sempre fazem a gente parar e pensar sobre se escolhemos o correto (Professor Antônio).

Olha já pensei em parar e ir pra outra área, isso ocorre principalmente ao final do ano quando queremos resultado, sem apoio da direção, e os alunos não têm uma cultura sobre a Educação Física e querem fazer o que querem (Professora Marta).

Quando iniciei na escola a gente para e pensa, e até dá vontade de jogar tudo para o alto, por passar por situações que jamais pensei em passar, como por exemplo, separar brigas, mães virem reclamar das aulas. Até o fato da própria escolha de ACT faz a gente pensar se vai continuar na profissão, porque todo ano é a mesma luta, é complicado (Professora Maria).

As falas acima nos permitem compreender que quaisquer que sejam as dificuldades encontradas pelos professores iniciantes podem fazer com que reflitam sobre a permanência na escola. Na fala da professora Maria é apontada que a reflexão sobre a permanência na docência já se inicia no processo de inserção dos professores ACT nas escolas, ou seja, isso desmotiva os docentes em início de carreira, pelo fato de não possuírem a certeza de que irão conseguir vagas para poderem atuar no contexto escolar.

Huberman (1995) faz menção ao "pôr-se em questão", que pode ser entendido como o "meio da carreira", sendo caracterizado pelas reflexões dos professores sobre suas escolhas passadas, ou seja, é quando os docentes analisam o que teriam feito em suas vidas como professores, e passam a se posicionar sobre o continuar ou desistir da carreira docente. Identificamos que o momento do "pôr-se em questão" acontece também no início da carreira, como analisamos nas falas das professoras Marta, Maria e do professor Antônio, sobre as dúvidas referentes à permanência e à insegurança de uma nova trajetória, e ao medo de ingressar e/ou de continuar na profissão.

Machado et al. (2010) corroboram com a ideia de que o professor desmotivado pode 
até permanecer no contexto escolar, mas não com o mesmo investimento pela docência, ou seja, apenas cumpre seus horários, sem refletir sobre suas aulas, processo esse chamado de desinvestimento pedagógico.

Já a fase da descoberta, no início da carreira, se traduz pelo fato de o docente estar sempre aberto e atento aos acontecimentos e às situações que o cercam. A sensação de responsabilidade pelos alunos e o entusiasmo inicial faz com que o docente iniciante se sinta mais forte e disposto a enfrentar o novo (HUBERMAN, 1995).

O professor José aponta na fala a seguir que mesmo o primeiro choque com a realidade faz com que consigam refletir e superar suas dificuldades iniciais:

A primeira impressão da realidade de cada escola dá um choque no primeiro momento, pelas condições de trabalho encontradas, falta de apoio, materiais, e até mesmo o salário, mas ao pararmos para refletir nossas práticas, quando tenho minha turma, meus alunos, quando se faz o que gosta é gratificante, quanto tu vê que pode fazer o mínimo por aquele aluno já é muito gratificante, isso me motiva (Professor José).

Gonçalves (1995, p. 164) observa que nesse período os "pés" se firmam no chão, pois "[...] a confiança foi alcançada, a gestão do processo de ensino-aprendizagem conseguida, a satisfação e um gosto pelo ensino [...] afirmam-se".

Quando os professores percebem que são responsáveis por algumas turmas, que possuem horários a cumprir, planos de aulas a fazer, reuniões para participar, enfim, quando se percebem parte da organização escolar, imersos no contexto, assumem toda a sua competência docente e desenvolvem sua própria autonomia, ou seja, se reconhecem professores.

\section{Considerações finais}

Constituíram-se como elementos significativos de análise neste processo, de acordo com a nossa interpretação, os choques com a realidade escolar que podem ocasionar nos professores em início de carreira o desinvestimento pedagógico. O desinvestimento também pode levá-los a um questionamento sobre a sua permanência na docência. Destaca-se, ainda, que os elementos formação inicial e atuação profissional, desvalorização da Educação Física e insatisfação financeira, se aplicam a todos de forma não linear e sistematizada, ou seja, cada caso se diferencia devido às particularidades dos sujeitos investigados.

A questão do professor ACT coloca o docente iniciante em um processo instável, pois fica a dúvida de se possuir ou não uma vaga na escola, de chegar o final do ano e seu contrato admissional terminar, de todos os anos mudar de escola e, aí, terem que iniciar seu processo de inserção numa escola. Assim, esse modelo de admissão em caráter temporário, potencializado na instabilidade e insegurança, precariza o trabalho docente e possibilita o não fortalecimento de vínculo com a cultura escolar.

A organização escolar está presente no cotidiano dos professores e é importante estar inserido no contexto para assim buscar um melhor entendimento desse espaço. A organização tem como função abrir/ampliar espaços e buscar, cada vez mais, meios de socialização e de construção de conhecimento. E essa organização, articulada ao trabalho docente, influencia na prática educativa dos professores iniciantes, pois assim eles se sentem mais seguros e 
confiantes para realizar a sua docência.

\title{
SCHOOL ORGANIZATION AND THE WORK TEACHER OF BEGINNERS PHYSICAL TEACHERS IN CRICIÚMA-SC CITY
}

\begin{abstract}
This study aims to understand how the school organization, linked to teaching, influences educational practice and working conditions of teachers of Physical Education beginners. It was investigated the educational practice and working conditions of six school teachers of Physical Education beginners who work in public schools. The instrument chosen was a semi-structured interview. We understand that the school organization has a primary role in the school context when articulated to teaching providing socialization among peers, and that working conditions offered to teachers can influence both the divestment as the process of discovery in teaching.
\end{abstract}

Keywords: School Organization. Teaching Work. Beginner Teacher Physical Education.

\section{LA ORGANIZACIÓN ESCOLAR Y EL TRABAJO DOCENTE DE PROFESORES PRINCIPIANTES DE EDUCACIÓN FÍSICA DE PROFESORES PRINCIPIANTES EL MUNICIPIO DE CRICIÚMA-SC}

\section{Resumen}

Este estudio tiene como objetivo comprender cómo la organización escolar, vinculado a la trabajo docente, influyen en la práctica educativa y en las condiciones de trabajo de los profesores principiantes de Educación Física principiantes. Investigamos la práctica educativa docente y las condiciones de trabajo de seis profesores que trabajan en las escuelas públicas. El instrumento elegido fue una entrevista semi-estructurada. Comprendemos que la organización de la escuela tiene un papel primordial en el contexto escolar cuando articulado al trabajo docente, proporcionando la socialización entre los pares, y que las condiciones de trabajo que se ofrecen a los profesores pueden influir tanto en la desinversión como el proceso de descubrimiento de la enseñanza.

Palabras clave: Organización Escolar. Trabajo Docente. Profesor de Educación Física Principiante.

\section{Referências}

ALMEIDA, L. de; FENSTERSEIFER, P. E. O lugar da experiência no âmbito da Educação Física. Movimento, Porto Alegre, v. 17, n. 4, out./dez. 2011. p. 247-263.

APPLE, M. W. Política cultural e educação. 2. ed. São Paulo: Cortez, 2001.

BASSO, I. S. Significado e sentido do trabalho docente. Caderno CEDES, Campinas, v. 19, n. 44, 1998.

CANCHERINI, A. A socialização do professor iniciante: um difícil começo. Dissertação. (Mestrado em Educação) - Programa de Pós-Graduação em Educação, Pontifícia Universidade Católica, Santos, 2009.

CONTRERAS, J. A autonomia de professores. 2. ed. São Paulo: Cortez, 2012. 
FRASSON, J. S. et al. Organização escolar: uma ponte para a socialização docente dos professores iniciantes. In: Congresso Internacional Sobre Professorado Principiante e Inserção Profissional à Docência, IV. Curitiba, 2014. Anais, Curitiba: Ed. UTFPR, 2014.

FREIRE, P. Pedagogia da autonomia. Rio de Janeiro: Paz e Terra, 1987.

GIROUX, H. A. Os professores como intelectuais transformadores: rumo a uma nova pedagogia crítica da aprendizagem. Porto Alegre: Artes Médicas, 1997.

GONÇALVES, J. A. M. A carreira dos professores de ensino primário. In: NÓVOA, A. (Org.). Vida de Professores. 2. ed. Porto: Porto Editora, 1995. p. 141-169.

HUBERMAN, M. Ciclo de vida profissional dos professores. In: NÓVOA, A. (Org.). Vida de Professores. 2. ed. Porto: Editora Porto, 1995.

MACHADO, T. da S. et al. As práticas de desinvestimento pedagógico na Educação Física escolar. Movimento, Porto Alegre, v. 16, n. 2, abr./jun. 2010. p. 129-147.

MARCELO GARCIA, C. O professor iniciante, a prática pedagógica e o sentido da experiência. Formação Docente, Belo Horizonte, v. 3, n. 3, 2010. p. 11-49.

MOLINA NETO, V. Etnografia: uma opção metodológica para alguns problemas e investigação no âmbito da Educação Física. In: MOLINA NETO, V.; TRIVIÑOS, A. N. S. (Org.). A pesquisa qualitativa em Educação Física: alternativas metodológicas. 3. ed. Porto Alegre: Sulina, 2010. p. 113-146.

NEGRINE, A. Instrumentos da coleta de informações na pesquisa qualitativa. In: MOLINA NETO, V.; TRIVIÑOS, A. N. S. (Org.). A pesquisa qualitativa na Educação Física: alternativas metodológicas. 3. ed. Porto Alegre: Sulina, 2010. p. 61-93.

NÓVOA, Antônio. A formação de Professores e profissão docente. In: NÓVOA, Antônio (Org.). Os Professores e sua formação. 2. ed. Lisboa: Dom Quixote, 1995. p. 15-33.

PÉREZ GÓMEZ, A. I. O pensamento prático do professor: a formação do professor como profissional reflexivo. In: NÓVOA, A. (Org.). Os Professores e sua formação. 2. ed. Lisboa: Dom Quixote, 1997. p. 93-114.

PÉREZ GÓMEZ, A. La cultura escolar en la sociedade neoliberal. Madri: Morata, 1998.

REALI, A. M. de M. R.; TANCREDI, R. M. S. P.; MIZUKAMI, M. da G. N. Programa de mentoria online para professores iniciantes: fases de um processo. Cadernos de Pesquisa, São Paulo, v. 40, n. 140, 2008. p. 479-506.

SANTOS, C. R. P. B. A escola pública, o trabalho docente e os professore iniciantes. Tese (Doutorado em Educação) - Faculdade de Educação, Universidade de São Paulo, São Paulo, 
2007.

TARDIF, M.; LESSARD, C. O trabalho docente: elementos para uma teoria da docência como profissão de interações humanas. Petrópolis: Vozes, 2005.

TRIVIÑOS, A. N. S. Introdução à pesquisa em ciências sociais: a pesquisa qualitativa em educação. São Paulo: Atlas, 1987.

WOODS, P. La escuela por dentro: la etnografia en la investigación educativa. Barcelona: Paidós, 1998.

ZEICHNER, K. M. Myths and realities: field-based experiences in preservice teacher education. Journal of Teacher Education, v. 31, n. 6, 1980. p. 45-49.

Recebido em: 06/02/2015

Revisado em: 17/08/2015

Aprovado em: 06/10/2015

Endereço para correspondência:

victorjulierme@yahoo.com.br

Victor Julierme Santos da Conceição

Universidade do Extremo Sul Catarinense

Av. Universitária, 1105

Bairro Universitário

88806-000 - Criciúma, SC - Brasil 